\title{
Reductive Electropolymerization and Electrochromism of Iron(II) Complex with Styrene-Based Ligand
}

\author{
Sergiusz Napierała, Kacper Muras, Grzegorz Dutkiewicz (D) and Monika Wałęsa-Chorab *(D) \\ Faculty of Chemistry, Adam Mickiewicz Unversity in Poznań, Uniwersytetu Poznańskiego 8, \\ 61-614 Poznań, Poland; sergiusz.napierala1999@gmail.com (S.N.); kacmur1@st.amu.edu.pl (K.M.); \\ gdutkiew@amu.edu.pl (G.D.) \\ * Correspondence: mchorab@amu.edu.pl
}

check for updates

Citation: Napierała, S.; Muras, K.; Dutkiewicz, G.; Wałęsa-Chorab, M. Reductive Electropolymerization and Electrochromism of Iron(II) Complex with Styrene-Based Ligand. Materials 2021, 14, 4831. https://doi.org/ $10.3390 / \mathrm{ma} 14174831$

Academic Editor: Yu-Wu Zhong

Received: 5 August 2021

Accepted: 21 August 2021

Published: 25 August 2021

Publisher's Note: MDPI stays neutral with regard to jurisdictional claims in published maps and institutional affiliations.

Copyright: (c) 2021 by the authors. Licensee MDPI, Basel, Switzerland. This article is an open access article distributed under the terms and conditions of the Creative Commons Attribution (CC BY) license (https:// creativecommons.org/licenses/by/ $4.0 /)$.

\begin{abstract}
The benzimidazole-based ligand containing polymerizable styrene group has been prepared via condensation of picolinaldehyde derivative containing styrene moiety and benzimidazolebased hydrazine. The ligand reacted with iron(II) tetrafluoroborate and iron(II) trifluoromethanesulfonate giving red-brown complexes of $\mathrm{Fe}(\mathrm{II})$ ions of formula $\left[\mathrm{FeL}_{2}\right] \mathrm{X}_{2}$, where $\mathrm{X}=\mathrm{CF}_{3} \mathrm{SO}_{3}{ }^{-}$(1) or $\mathrm{BF}_{4}{ }^{-}$(2). Reductive electropolymerization was used to obtain a thin layer of the polymeric complex, poly-1. Further investigation of electrochemical properties of the compound by cyclic voltammetry showed two quasi-reversible redox processes assigned to electrooxidation and electroreduction of the polymer. Spectroelectrochemical measurements confirmed that the polymer undergoes the color changes during oxidation and reduction process. The polymer in its neutral state (Fe(II)) is yellow and it exhibits absorption band at $370 \mathrm{~nm}$, after oxidation to Fe(III) state absorption band shifts to $350 \mathrm{~nm}$ and the polymer is almost colorless. While the metal ions are reduced to Fe(I) absorption band at around $410 \mathrm{~nm}$ has been observed and the polymer changed its color to intense yellow. The stability of the polymer during multiple oxidation/reduction cycles has also been investigated.
\end{abstract}

Keywords: reductive electropolymerization; iron(II) complex; $\mathrm{N}_{3}$-donor ligand; electrochromism

\section{Introduction}

Electropolymerization it is the well-known method of formation of thin, insoluble layers of polymeric materials, in which the formation of the polymer occurs directly on the surface of the conductive substrates [1]. The advantage of the use of electropolymerization as a method of formation of thin films is that only a good solubility of the monomers is required and this way the solubility problem of the polymer is avoided. By adjusting the duration of the electropolymerization the surface coverage and film thickness can be easily controlled. Electropolymerized films are adhesive, stable and electrochemically active. It is also possible to perform the electrochemical copolymerization of monomers, which is highly effective for producing multicolor electrochromic polymers [2-4]. Because of these features, electropolymerization has become an important method for making thin films for applications in various electronic devices.

Although oxidative electropolymerization occurs in the majority of cases [5-8], reductive electropolymerization that undergoes on the cathode is also possible. Reductive electropolymerization has been found to be an efficient method of formation of thin films of polymers derived from pyridyl and polypyridyl complexes containing styrene groups [9-15]. The mechanism of reductive electropolymerization of complexes containing vinyl-substituted ligands is believed to be anionically initiated $[16,17]$, followed by $C-C$ bond formation as a result of the reaction between formed radicals and side-by-side chain propagation [18]. The reductive electropolymerization of vinyl-substituted complexes has been also useful for the copolymerization of various metal complexes [11,19]. The polymerization of compounds containing styrene groups leading to formation of thin films on the electrode surface can also be done by radical polymerization reaction $[20,21]$ but 
it usually requires the use of some additional initiators, such as AIBN or temperature to initiate the formation of free radicals.

Hydrazone $\mathrm{N}_{3}$-donor ligands are known to be analogues of terpyridines having the same coordination preferences and forming complexes of similar structures. The advantage of hydrazone ligands over their terpyridine counterparts is a straightforward synthesis via condensation reaction of aldehydes or ketones with appropriate hydrazine derivative, while the terpyridines are usually obtaining via multistep condensation or coupling reactions [22-24]. Besides being easier to synthesize, hydrazone ligands, due to this fact that the only one byproduct of the condensation reaction is water, can be purified by simple crystallization in comparison to the terpyridines that are usually purifying by column chromatography. Also, the synthesis of both hydrazones and Schiff-base ligands usually occur in ethanol decreasing the use of toxic and harmful organic solvents [25].

Herein we present the synthesis of hydrazone $\mathrm{N}_{3}$-donor ligand and its complexes with $\mathrm{Fe}(\mathrm{II})$ ions. The complexes have been designed to possess two styrene groups that undergo reductive electropolymerization during multiple electrochemical cycles. Complexes have been characterized by spectroscopic methods, as well as by X-ray diffraction analysis confirming the 1:2 metal: ligand stoichiometry. The complex $\mathbf{1}$ has been successfully electropolymerized on the ITO electrode surface and its electrochemical and electrochromic properties have been investigated.

\section{Materials and Methods}

\subsection{General}

The aldehyde $\mathbf{A}$ and the benzimidazole derivative $\mathbf{B}$ have been obtained according to a previously reported procedures $[20,26,27]$. NMR spectra were recorded on a Bruker UltraShield $300 \mathrm{MHz}$ spectrometer (Bruker Corporation, Billerica, MA, USA) and were calibrated against the residual protonated solvent signal $\left(\mathrm{d}_{6}-\mathrm{DMSO}, \delta 2.50 \mathrm{ppm}\right)$. Highresolution mass spectra were run on a QTOF spectrometer (Impact HD Brucker, Bruker Daltonics, Bremen, Germany) in positive ion mode. A conventional three-electrode cell was used for electrochemical measurements with a platinum electrode as the working electrode, a platinum wire as the counter electrode and a non-aqueous $\mathrm{Ag} / \mathrm{Ag}^{+}$electrode as the reference electrode. The supporting electrolyte was $0.1 \mathrm{M}$ solution of tetrabutylammonium perchlorate $\left(\mathrm{TBAClO}_{4}\right)$ in acetonitrile. The acetonitrile for the preparation of the supporting electrolyte was dried by passing over neutral alumina followed by the storage over $3 \AA$ molecular sieves [28]. The electrolyte before measurements was purged with argon for $20 \mathrm{~min}$. to remove the dissolved oxygen and the argon blanket was maintained over the solution to prevent oxygen diffusion during measurements. The cyclic voltammograms were obtained using a VSP multichannel potentionstat (BioLogic, Seyssinet-Pariset, France). The spectroelectrochemical measurements in solution were done using commercially available honeycomb electrode (Pine Research Instrumentation, Inc., Durham, NC, USA). The spectroelectrochemistry of the polymer was done using a polymer modified indium-tin oxide coated (ITO) glass slides, Pt wire as a counter electrode and a silver wire as a pseudoreference electrode. The SEM images were done on the scanning electron microscope (Quanta 250 FEG, Thermo Fisher Scientific wissenschaft-liche Geräte GmbH, Wien, Austria), AFM images were done using atomic force microscope (Agilent 5500, Agilent Technologies Ltd., Yarnton, UK).

\subsection{Synthesis}

Ligand L: To a solution of aldehyde A $(0.25 \mathrm{~g}, 1.2 \mathrm{mmoL})$ in ethanol $(10 \mathrm{~mL})$, benzimidazole derivative $\mathbf{B}(0.19 \mathrm{~g}, 1.2 \mathrm{mmoL})$ was added. The mixture was stirred at room temperature under an argon atmosphere overnight. The crude product was isolated by evaporation of the solvent. Afterward, the residue was solubilized in a minimum volume of dichloromethane and the final product was obtained via crystallization by gradual addition of hexane. Yield: $62.31 \%(0.2638 \mathrm{~g}) .{ }^{1} \mathrm{H}$ NMR $(300 \mathrm{MHz}, \mathrm{DMSO}) \delta 11.91(\mathrm{~s}, 1 \mathrm{H})$, $8.40(\mathrm{dd}, J=7.2,1.6 \mathrm{~Hz}, 1 \mathrm{H}), 8.15(\mathrm{~d}, J=8.3 \mathrm{~Hz}, 2 \mathrm{H}), 7.99-7.85(\mathrm{~m}, 3 \mathrm{H}), 7.61(\mathrm{~d}, J=8.2 \mathrm{~Hz}$, 
2H), 7.45-7.31 (m, 2H), 7.10-7.00 (m, 2H), $6.81(\mathrm{dd}, J=17.6,11.0 \mathrm{~Hz}, 1 \mathrm{H}), 5.93$ (dd, $J=17.7$, $1.0 \mathrm{~Hz}, 1 \mathrm{H}), 5.33(\mathrm{dd}, J=10.8,1.0 \mathrm{~Hz}, 1 \mathrm{H}), 3.73(\mathrm{~s}, 3 \mathrm{H}) \mathrm{ppm} .{ }^{13} \mathrm{C}$ NMR $(75 \mathrm{MHz}, \mathrm{DMSO})$ $\delta 155.1,154.1,153.4,142.7,137.9,137.7,137.5,137.0,136.2,134.2,126.8,126.5,120.8,120.1$, 119.4, 118.5, 116.5, 115.1, 31.8 ppm. HR-MS (ESI) $m / z$ : $[\mathrm{L}+\mathrm{H}]^{+}$calcd. for $\mathrm{C}_{22} \mathrm{H}_{20} \mathrm{~N}_{5} 354.1714$; found 354.1716; [L+Na] ${ }^{+}$calcd. for $\mathrm{C}_{22} \mathrm{H}_{19} \mathrm{~N}_{5} \mathrm{Na}$ 376.1533; found 376.1537. Elemental analysis calcd. for $\mathrm{C}_{22} \mathrm{H}_{19} \mathrm{~N}_{5} \mathrm{C}, 74.77 ; \mathrm{H}, 5.42 ; \mathrm{N}, 19.82$; found $\mathrm{C}, 74.75 ; \mathrm{H}, 5.48 ; \mathrm{N}, 19.84$.

Synthesis of complexes-general procedure: A mixture of ligand $\mathbf{L}$ and an appropriate iron(II) salt in 1:2 ligand to metal molar ratio was solubilized in a dichloromethane/acetonitrile mixture 2:1 $(v / v)$ and the solution was stirred at room temperature for $24 \mathrm{~h}$ under the normal atmosphere. The solution was concentrated and diethyl ether was added to precipitate the complex. The obtained solid was centrifuged, washed with diethyl ether and dried.

Complex 1: Obtained as a dark-red solid. Yiled: 69\% (42 mg). HR-MS (ESI) $m / z$ : $\left[\mathrm{FeL}_{2}\right]^{2+}$ calcd. for $\mathrm{C}_{44} \mathrm{H}_{38} \mathrm{~N}_{10} \mathrm{Fe} 381.1310$; found 381.1306; [FeL(L-H)]+ calcd. for $\mathrm{C}_{44} \mathrm{H}_{37} \mathrm{~N}_{10} \mathrm{Fe}$ 761.2547; found 761.2546. Elemental analysis calcd. for $\mathrm{Fe}\left(\mathrm{C}_{22} \mathrm{H}_{19} \mathrm{~N}_{5}\right)\left(\mathrm{CF}_{3} \mathrm{SO}_{3}\right)_{2} \mathrm{C}, 52.08$; H, 3.61; N, 13.20; S, 6.05; found C, 52.14; H, 3.63; N, 13.19; S, 6.04.

Complex 2: Obtained as a red solid. Yield: 63\% (25 mg). HR-MS (ESI) $m / z:\left[\mathrm{FeL}_{2}\right]^{2+}$ calcd. for $\mathrm{C}_{44} \mathrm{H}_{38} \mathrm{~N}_{10} \mathrm{Fe} 381.1310$; found 381.1315. Elemental analysis calcd. for $\mathrm{Fe}\left(\mathrm{C}_{22} \mathrm{H}_{19} \mathrm{~N}_{5}\right)$ $\left(\mathrm{BF}_{4}\right)_{2} \mathrm{C}, 56.44 ; \mathrm{H}, 4.09 ; \mathrm{N}, 14.96$; found $\mathrm{C}, 56.43 ; \mathrm{H}, 4.14 ; \mathrm{N}, 14.93$.

\subsection{X-ray Crystallography}

Diffraction data were collected by the $\omega$-scan technique, using graphite-monochromated $\operatorname{MoK}_{\alpha}$ radiation $(\lambda=0.71073 \AA)$, at room temperature (1) and at $100(1) \mathrm{K}(2)$ on Rigaku Xcalibur four-circle diffractometer with EOS CCD detector (Agilent Technologies Ltd., Yarnton, UK). The data were corrected for Lorentz-polarization as well as for absorption effects [29]. Precise unit-cell parameters were determined by a least-squares fit of the reflections of the highest intensity, chosen from the whole experiment. The structures were solved with SHELXT [30] and refined with the full-matrix least-squares procedure on $\mathrm{F}^{2}$ by SHELXL [31]. All non-hydrogen atoms were refined anisotropically. Hydrogen atoms were placed in idealized positions and refined as 'riding model' with isotropic displacement parameters set at $1.2\left(1.5\right.$ for $\left.\mathrm{CH}_{3}\right)$ times $\mathrm{U}_{\mathrm{eq}}$ of appropriate carrier atoms. The crystals of $\mathbf{1}$ has been twinned, and this was taken into account both during date reduction [29] and structure refinement [30]; the BASF factor, related to the ratio of both components, refined at $0.3553(17)$. In the structure of 2 large voids have been found, filled with diffused electron density-probably highly disordered solvent. As the attempts to model the reasonable solvent model failed, the SQUEEZE procedure has been successfully applied. Crystal data, data collection and structure refinement are shown in Table 1.

Table 1. Crystal data, data collection and structure refinement.

\begin{tabular}{ccc}
\hline Compound & $\mathbf{1}$ & $\mathbf{2}$ \\
\hline Formula & $\mathrm{C}_{44} \mathrm{H}_{38} \mathrm{FeN}_{10}{ }^{2+}$ & $2\left(\mathrm{C}_{44} \mathrm{H}_{38} \mathrm{FeN}_{10}\right)^{2+}$ \\
Formula weight & $2 \mathrm{CF}_{3} \mathrm{SO}_{3}-\cdot \mathrm{C}_{2} \mathrm{H}_{6} \mathrm{O}$ & $4 \mathrm{BF}_{4}-\cdot 5 \mathrm{C}_{2} \mathrm{H}_{3} \mathrm{~N}$ \\
Crystal system & 1106.90 & 2073.86 \\
Space group & hexagonal & monoclinic \\
a $(\AA)$ & $\mathrm{P}_{3}$ & $\mathrm{Cc}$ \\
$\mathrm{b}(\AA)$ & $21.3035(3)$ & $31.2280(10)$ \\
$\mathrm{c}(\AA)$ & $21.3035(3)$ & $11.6807(5)$ \\
$\alpha\left(^{\circ}\right)$ & $21.4739(3)$ & $29.1181(17)$ \\
$\beta\left({ }^{\circ}\right)$ & 90 & 90 \\
$\gamma\left({ }^{\circ}\right)$ & 90 & $92.196(4)$ \\
$\mathrm{V}\left(\AA^{3}\right)$ & 120 & 90 \\
$\mathrm{Z}$ & $8440.0(3)$ & $10,613.5(8)$ \\
$\mathrm{D}_{\mathrm{x}}\left(\mathrm{g} \mathrm{cm}^{-3}\right)$ & 6 & 1 \\
$\mathrm{~F}(000)$ & 1.307 & 1.298 \\
& 3420 & 4264 \\
\hline
\end{tabular}


Table 1. Cont.

\begin{tabular}{ccc}
\hline Compound & $\mathbf{1}$ & $\mathbf{2}$ \\
\hline$\mu\left(\mathrm{mm}^{-1}\right)$ & 0.417 & 0.358 \\
Reflections: & & \\
collected & 72,901 & 22,167 \\
unique $\left(\mathrm{R}_{\text {int }}\right)$ & $68,984(0.0334)$ & $14,487(0.0458)$ \\
with $\mathrm{I}>2 \sigma(\mathrm{I})$ & 60,314 & 8953 \\
$\mathrm{R}(\mathrm{F})[\mathrm{I}>2 \sigma(\mathrm{I})]$ & 0.0534 & 0.0722 \\
$\mathrm{wR}\left(\mathrm{F}^{2}\right)[\mathrm{I}>2 \sigma(\mathrm{I})]$ & 0.1353 & 0.1789 \\
$\mathrm{R}(\mathrm{F})[$ all data] & 0.0630 & 0.1141 \\
$\mathrm{wR}\left(\mathrm{F}^{2}\right)[$ all data] & 0.1420 & 0.2017 \\
$\mathrm{Goodness}$ of fit & 1.055 & 1.092 \\
max $/$ min $\Delta \rho\left(\mathrm{e} \cdot \AA^{-3}\right)$ & $0.91 /-0.25$ & $0.45 /-0.61$ \\
$\mathrm{CCDC}$ deposition number & $2,081,073$ & $2,081,074$ \\
\hline
\end{tabular}

\section{Results and Discussion}

The ligand $\mathbf{L}$ has been obtained via condensation reaction between picolinaldehyde containing styrene group A and benzimidazole-based hydrazine $\mathbf{B}$ as outlined in Figure 1.<smiles>C=Cc1ccc(-c2cccc(C=O)n2)cc1</smiles>

A<smiles>CN(N)c1nc2ccccc2[nH]1</smiles>

B<smiles>C=Cc1ccc(-c2cccc(/C=N/N(C)c3nc4ccccc4[nH]3)n2)cc1</smiles>

$\mathbf{L}$

Figure 1. Synthetic scheme of preparation of $\mathbf{L}$.

The reaction was carried out in an absolute ethanol for $24 \mathrm{~h}$ at room temperature. The ligand $\mathbf{L}$ has been obtained as a slightly yellow crystalline solid with the yield of $63 \%$ via crystallization from a dichloromethane/hexane. The ligand L has been used in complexation reactions with two different salts of Fe(II) ions: tetrafluoroborate and trifluoromethanesulfonate. The complexation reactions were done at room temperature for $24 \mathrm{~h}$ in dichloromethane/acetonitrile 2:1 $(v / v)$ mixture and the complexes of stoichiometry metal:ligand 1:2 have been obtained as red-brown colored solids via evaporation of the solvent and precipitation from a minimum volume of acetonitrile by gradual addition of diethyl ether. The complexes have been characterized using spectroscopic methods. In the ESI-MS spectra of complexes peaks at $m / z=381$ and 761 have been observed that are associated with the presence of $\left[\mathrm{FeL}_{2}\right]^{2+}$ and $[\mathrm{FeL}(\mathbf{L}-\mathrm{H})]^{+}$molecular cations in solution. The ESI spectra of complexes contain also the signals at $m / z=354$ and 376 that have been assigned to molecular cations $[\mathrm{L}+\mathrm{H}]^{+}$and $[\mathrm{L}+\mathrm{Na}]^{+}$. The presence of these signals suggest the instability of investigated complexes under ESI conditions.

The unambiguous structures of complexes have been investigated by X-ray crystallography. The single crystals appropriate for X-ray measurements were grown by slow diffusion of diethyl ether into acetonitrile solutions of complexes. Figure 2 shows the perspective views of the dications 1 and 2; Table 2 lists the relevant geometrical parameters. As expected, all complexes are of $\mathrm{ML}_{2}$ structure, and the overall shapes and coordinations of all three dications (in the structure 2 there are two symmetry-independent complexes) are very similar (Figure 2). The coordination of metal cation is best described as (highly) distorted octahedral one (cf. Table 2), with quite linear N12-Fe-N12 angle. 
A)

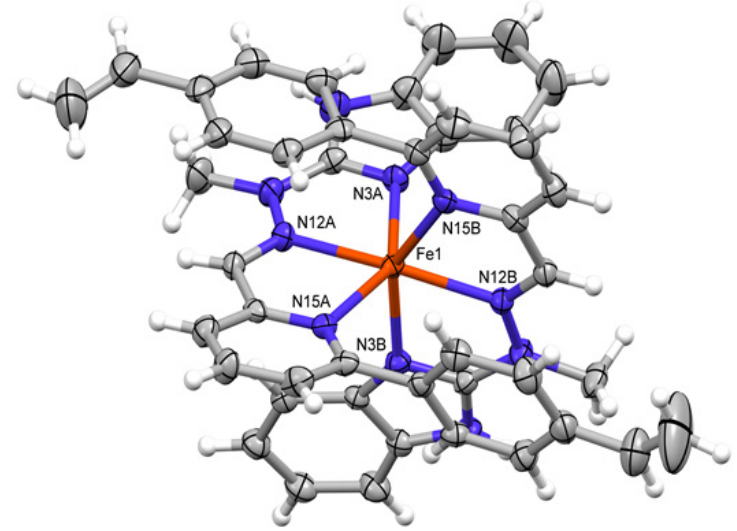

B)

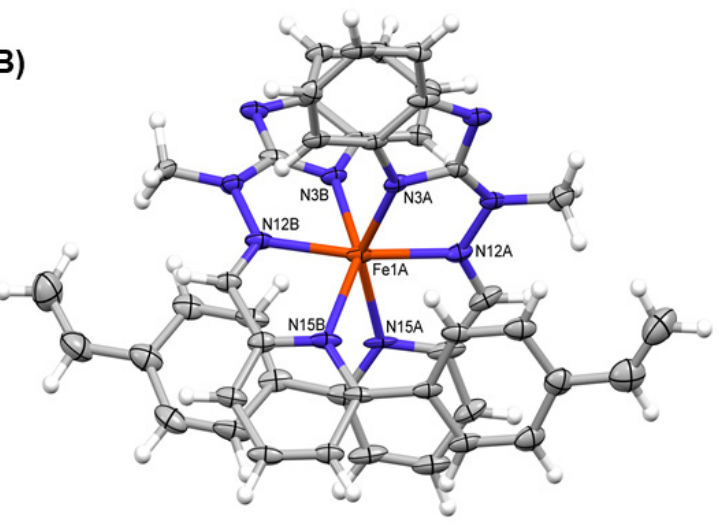

Figure 2. Perspective views of the cation observed in the structure $\mathbf{1}(\mathbf{A})$ and one of the symmetry-independent cationic complexes of $\mathbf{2}$ (B). Ellipsoids are drawn at the 50\% probability level, hydrogen atoms are shown as spheres of arbitrary radii.

Table 2. Relevant geometrical parameters $\left(\AA^{\circ}{ }^{\circ}\right)$ with s.u.'s in parentheses.

\begin{tabular}{cccc}
\hline & $\mathbf{1}$ & $\mathbf{2 A}$ & 2B \\
\hline \multirow{2}{*}{ Fe-N3 } & $2.142(6)$ & $2.137(7)$ & $2.131(7)$ \\
& $2.153(6)$ & $2.145(7)$ & $2.133(8)$ \\
\hline \multirow{2}{*}{ Fe-N12 } & $2.150(7)$ & $2.140(10)$ & $2.117(9)$ \\
& $2.161(7)$ & $2.159(10)$ & $2.126(10)$ \\
\hline \multirow{2}{*}{ Fe-N15 } & $2.202(7)$ & $2.257(8)$ & $2.244(7)$ \\
& $2.281(7)$ & $2.266(8)$ & $2.269(8)$ \\
\hline \multirow{2}{*}{ Angles } & $166.6(2)$ & $171.9(3)$ & $171.1(3)$ \\
& $146.7(2)$ & $146.4(4)$ & $145.6(3)$ \\
& $145.9(2)$ & $146.0(4)$ & $145.9(4)$ \\
\hline
\end{tabular}

To examine the usefulness of complexes as active materials in electronic devices they have been investigated in terms of their electrochemical properties. The solution electrochemical data for complexes $\mathbf{1}$ and $\mathbf{2}$ were obtained by cyclic voltammetry. The measurements were done in the three-electrode configuration in deaerated, anhydrous acetonitrile solution of tetrabutylammonium perchloride $(0.1 \mathrm{M})$ as a supporting electrolyte. In case of complex 1 the two quasi-reversible oxidation/reduction waves have been observed with the half-wave potentials of $-0.29 \mathrm{~V}$ and $+0.76 \mathrm{~V}$ (Figure 3).

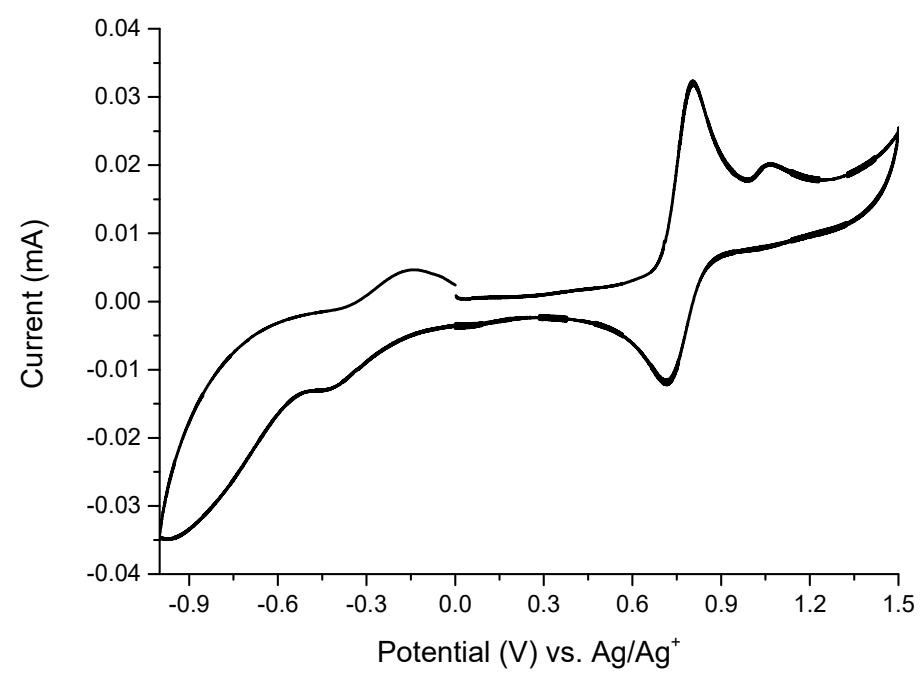

Figure 3. Cyclic voltammogram of complex 1 measured in anhydrous and deaerated acetonitrile with $0.1 \mathrm{M} \mathrm{TBAClO}_{4}$ as a supporting electrolyte at scan rate $100 \mathrm{mV} \cdot \mathrm{s}^{-1}$. 
The two electrochemical processes can be assigned to redox couples $\left[\mathrm{Fe}(\mathrm{I}) \mathbf{L}_{2}\right]^{+} /\left[\mathrm{Fe}(\mathrm{II}) \mathbf{L}_{2}\right]^{2+}$ and $\left[\mathrm{Fe}(\mathrm{II}) \mathbf{L}_{2}\right]^{2+} /\left[\mathrm{Fe}(\mathrm{III}) \mathbf{L}_{2}\right]^{3+}$, respectively [32-34]. One additional irreversible wave assigned to the oxidation of the ligand molecule has been observed at $+1.07 \mathrm{~V}$ in the anodic scan. In case of complex 2 the quasi-reversible redox wave at $\mathrm{E}_{1 / 2}=+0.76 \mathrm{~V}$ assigned to the oxidation of the metallic center has been observed. In the cathodic part of the cyclic voltammogram, the small quasi-reversible wave at $\mathrm{E}_{\mathrm{pc}}=-0.18 \mathrm{~V}$ was noticed. This wave can be attributed to $\mathrm{Fe}(\mathrm{II}) / \mathrm{Fe}(\mathrm{I})$ redox couple (Figure S1). It has been known that when the value of $i_{p c} / i_{p a}$ is closer to 1 at the same scan rate, a more reversible reaction is expected [35]. As calculated for $\mathrm{Fe}(\mathrm{II}) / \mathrm{Fe}(\mathrm{III})$ redox couple the $\mathrm{i}_{\mathrm{pc}} / \mathrm{i}_{\mathrm{pa}}$ value for complexes $\mathbf{1}$ and 2 were found to be 0.7 and 0.3 , respectively. The $i_{p c} / i_{p a}$ values lower than 1 indicate that the oxidation product is unstable and decompose. Due to complex 1 exhibited better electrochemical reversibility than 2 , it has been chosen for further investigations of electrochemical and electrochromic properties. To improve the reversibility of Fe(II)/Fe(III) redox couple we investigated the electrochemical properties on complex $\mathbf{1}$ in the narrower potential window up to $+1.0 \mathrm{~V}$ to avoid the oxidation of ligand molecules (Figure S2). As expected, the reversibility of the anodic process increased and the $i_{p c} / i_{p a}$ value was calculated to be 0.85 , what indicates that the decomposition of the complex during redox reaction was partially caused by the decomposition of oxidized ligand molecule.

When the potential was scanned repeatedly between $-1.0 \mathrm{~V}$ and $-2.0 \mathrm{~V}$, the current increased gradually and continuously (Figure 4A). This indicates the in situ deposition of polymeric film on the electrode surface as a result of reductive electropolymerization of vinyl groups. It was observed that the cathodic peak currents of the forward scans are much higher that the anodic peak currents of the reverse scans. This is probably due to the partial decomposition of the reduced monomers but, despite this, the formation of thin layer of polymers on the electrode surface has been observed. The electrode was rinsed with copious amounts of $\mathrm{CH}_{3} \mathrm{CN}$ and then measured in a clean supporting electrolyte solution (Figure S3). The well-defined Fe(II)/Fe(III) and Fe(II)/Fe(I) couples are retained and the potential remains basically unchanged after polymerization similarly as observed for vinyl-containing polypyridyl ruthenium complexes [11]. To investigate whether the redox process is controlled by diffusion or adsorption the cyclic voltammograms of poly-1 at different scan speeds were recorded (Figure 4B). The shift of the anodic peak potentials towards more negative potentials upon increasing the scan rate was observed, and similarly the cathodic peak shifted towards more positive potential with the increase of the scan speed. This indicates the presence of the electrochemical irreversibility and the quasireversible redox process. As revealed in Figure $4 \mathrm{C}$, when the scan rate was different from 50 to $1000 \mathrm{mV} / \mathrm{s}$, a linear dependence with the linear regression coefficient of $\mathrm{R}^{2}=0.9982$ of the redox response upon the scan rate $(v)$ was detected, and it indicates that the redox events occur at the electrode surface [36].

The electropolymerization of $\mathbf{1}$ on ITO electrode produced the formation of adherent polymeric film. The morphology of the formed layer was investigated by scanning electron microscopy (SEM) and atomic force microscopy (AFM). As seen in Figure 5 the surface of the polymeric thin film is smooth and flat except for the presence of small irregular domains.

The film thickness was investigated using AFM scratch method. To do this, the polymeric film was cutted with the blade and the difference between the polymeric film and bare ITO surface was measured in few different places by AFM (Figure 6). 

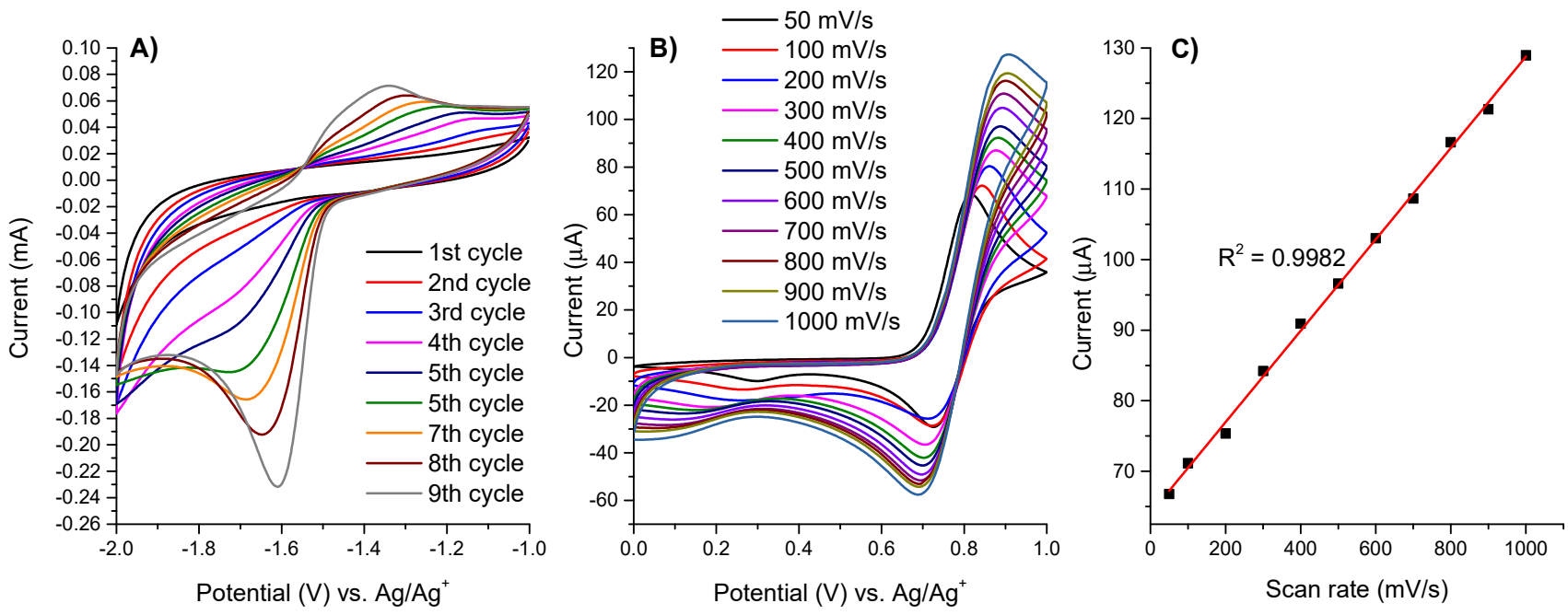

Figure 4. (A) Reductive electropolymerization of $\mathbf{1}$ in $0.1 \mathrm{M}$ solution of $\mathrm{TBAClO}_{4}$ in deaerated and anhydrous acetonitrile on ITO glass electrode by 10 repeated cyclic potential scans between $-1.0 \mathrm{~V}$ and $-2.0 \mathrm{~V}$ at scan rate of $100 \mathrm{mV} / \mathrm{s}$; (B) CV profiles of the poly-1 film obtained at different scan rates; (C) Linear dependence on the scan rates of the anodic peak currents of the poly-1 film.
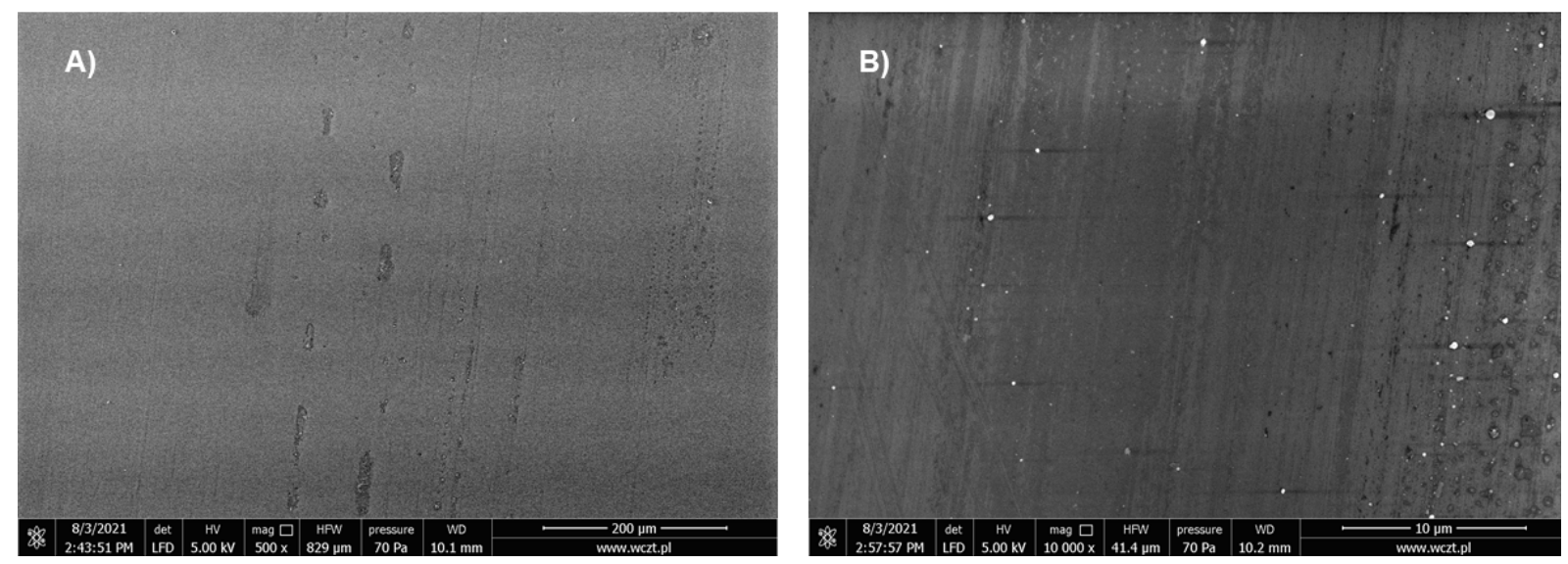

Figure 5. SEM image of the thin film of polymer poly-1 with magnification $500 \times(\mathbf{A})$ and $10,000 \times(B)$.

A)

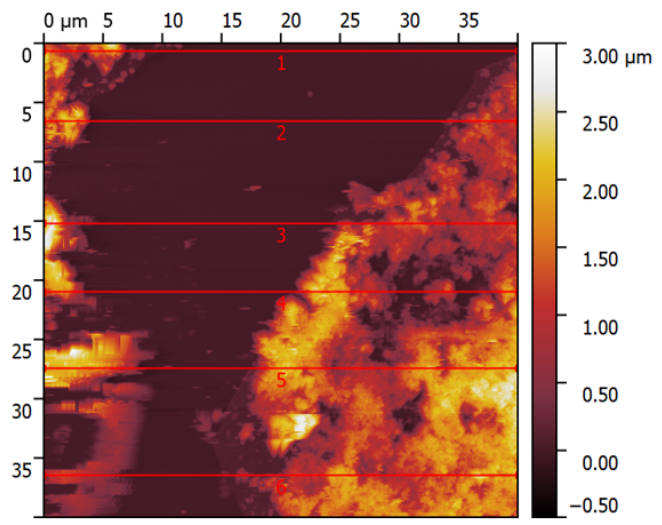

B)

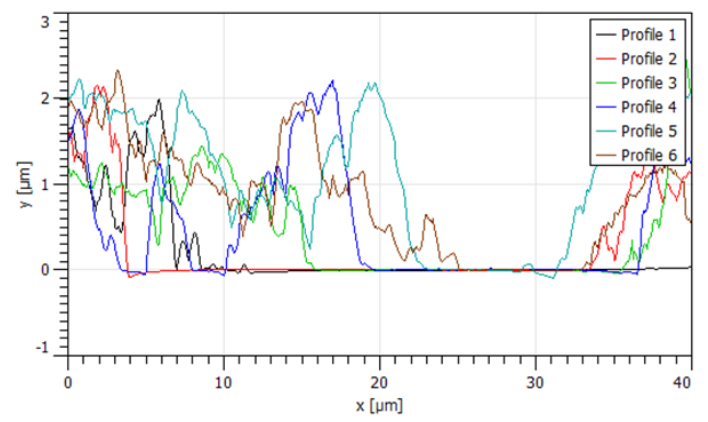

Figure 6. (A) AFM micrographs of poly-1 at a $40 \mu \mathrm{m} \times 40 \mu \mathrm{m}$ resolution scale deposited on ITO electrodes showing the step between the ITO and the polymer surface. (B) AFM cross-section profiles measured at a marked places. 
The film was found to have the average thickness of $\sim 1.5 \mu \mathrm{m}$. Root mean square (RMS) roughness parameter measured by atomic force microscopy (AFM) was calculated to be $153 \mathrm{~nm}$.

The polymer poly-1 was further investigated by spectroelectrochemistry in terms of the color change in response to an electric stimulus and its electrochromic properties has been compared with the properties of monomer 1 in solution. The advantage of spectrolectrochemistry is the cross-correlation of the information from both electrochemical and optical measurements and it allows to investigate the absorption changes resulting from species produced or consumed in the electrochemical process [37]. For both $\mathbf{1}$ in solution and poly-1 the visible color changes have been observed during oxidation and reduction process (Figure 7 and Figure S4).

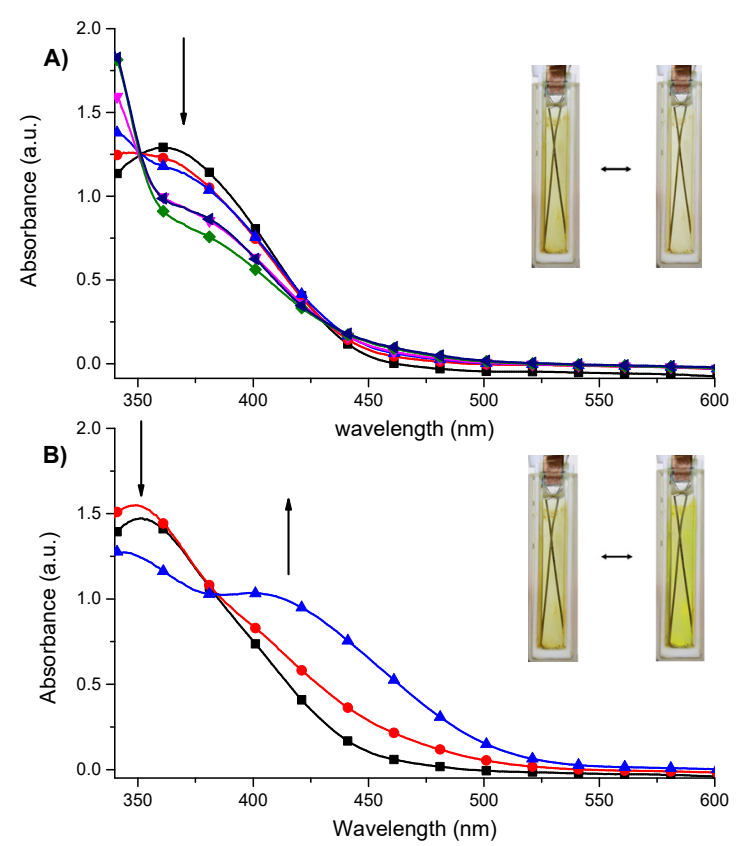

Figure 7. Spectroelectrochemistry of poly-1 immobilized on ITO electrode measured in anhydrous and deaerated $0.1 \mathrm{M}$ solution of $\mathrm{TBAClO}_{4}$ in acetonitrile as a supporting electrolyte with applied potentials of $(\mathbf{A}) 0(\mathbf{\square}),+500(\bullet),+600(\mathbf{\Delta}),+700(\mathbf{\nabla}),+800(\triangleleft)$ and $+900(\downarrow) \mathrm{mV}$ held for 30 s per potential; insert: the photograph of poly-1 in its neutral (left) and electrochemically oxidized (right) states; (B) $-100(\mathbf{\square}),-200(\bullet)$ and $-300(\mathbf{\Delta}) \mathrm{mV}$ held for 30 s per potential; insert: the photograph of poly-1 in its neutral (left) and electrochemically reduced (right) states.

The complex 1 in $\mathrm{Fe}(\mathrm{II})$ state exhibits one absorption band at $370 \mathrm{~nm}$ attributed to metal-to-ligand charge transfer (MLCT). Upon electropolymerization, a slight blue shift $(\sim 7 \mathrm{~nm}$ to $363 \mathrm{~nm})$ of this band was observed for the surface-grafted poly-1 in comparison to monomer $\mathbf{1}$ in solution. It is probably due to conversion of the electron-withdrawing vinyl groups in $\mathbf{1}$ to saturated alkyl groups in the polymeric network during the reductive electropolymerization process [14]. When the positive potential was applied to poly-1 the disappearance of the MLCT band was observed (Figure 7A). It was concomitant with the formation of ligand-to-metal charge transfer (LMCT) band with the absorption maxima in the ultraviolet region, below $350 \mathrm{~nm}$ [38-40]. It was the result of electrooxidation of Fe(II) ions and formation of the Fe(III) complex on ITO surface. The sharp isosbestic point at $350 \mathrm{~nm}$ indicates the presence of only neutral and oxidized species in the polymeric film and their independence. During this process the color of the film changed from yellow to almost colorless. After applying of negative potential to poly- $\mathbf{1}$ the formation of the band at around $410 \mathrm{~nm}$ was observed as a result of the reduction of Fe(II) to Fe(I) ions (Figure 7B). The poly-1 in its reduced form was found to exhibit intense yellow color. Similar optical 
changes have been observed for $\mathbf{1}$ in solution (Figure S4). The absorption spectra of poly-1 in its different redox states have been shown in Figure S5.

To investigate the electrochromic properties of poly-1 in details, a chronoamperometry coupled with the UV-Vis spectroscopy was used to evaluate the long term stability of the film, switching time, optical contrast and coloration efficiency. The biggest difference in transmittance of oxidized and reduced states of poly-1 was found to be $51 \%$ at the wavelength of $450 \mathrm{~nm}$ (Figure $8 \mathrm{~A}$ ). The changes in $\Delta \mathrm{T} \%$ values were measured by switching the potential between $+1.0 \mathrm{~V}$ and $-0.5 \mathrm{~V}$ with the time intervals from $40,30,20$ to $10 \mathrm{~s}$ to assay the influence of the retention times on the contrast ratios of the polymer (Figure $8 \mathrm{~B}$ ). For poly-1 the contrast ratio at $450 \mathrm{~nm}$ decreased from $50 \%$ to $23.1 \%$ after 10 switching cycles with $40 \mathrm{~s}$ interval, what indicates the gradual degradation of the polymeric film during multiple electrochemical processes. Then, the transmittance difference decreased to $22 \%$ when the intervals was changed to $30 \mathrm{~s}$, through $16.5 \%$ for $20 \mathrm{~s}$ intervals to $13.3 \%$ for $10 \mathrm{~s}$ intervals. The poly-1 was found to be stable during switching with $20 \mathrm{~s}$ and $10 \mathrm{~s}$ intervals; the transmittance difference did not change after 10 oxidation/reduction cycles. To further investigate the long-term stability of the poly-1 potential was switched between $+1.0 \mathrm{~V}$ and $-0.5 \mathrm{~V}$ with $10 \mathrm{~s}$ intervals and the transmittance at $450 \mathrm{~nm}$ was investigated. As seen in Figure 8C the transmittance difference dropped down from $13.3 \%$ to $5 \%$ after 70 oxidation/reduction cycles (1400 s), what was probably caused the degradation of the polymer. The improvement of the stability of the layer for electronic applications could be achieved by increasing the degree of the cross-linking [41-43].
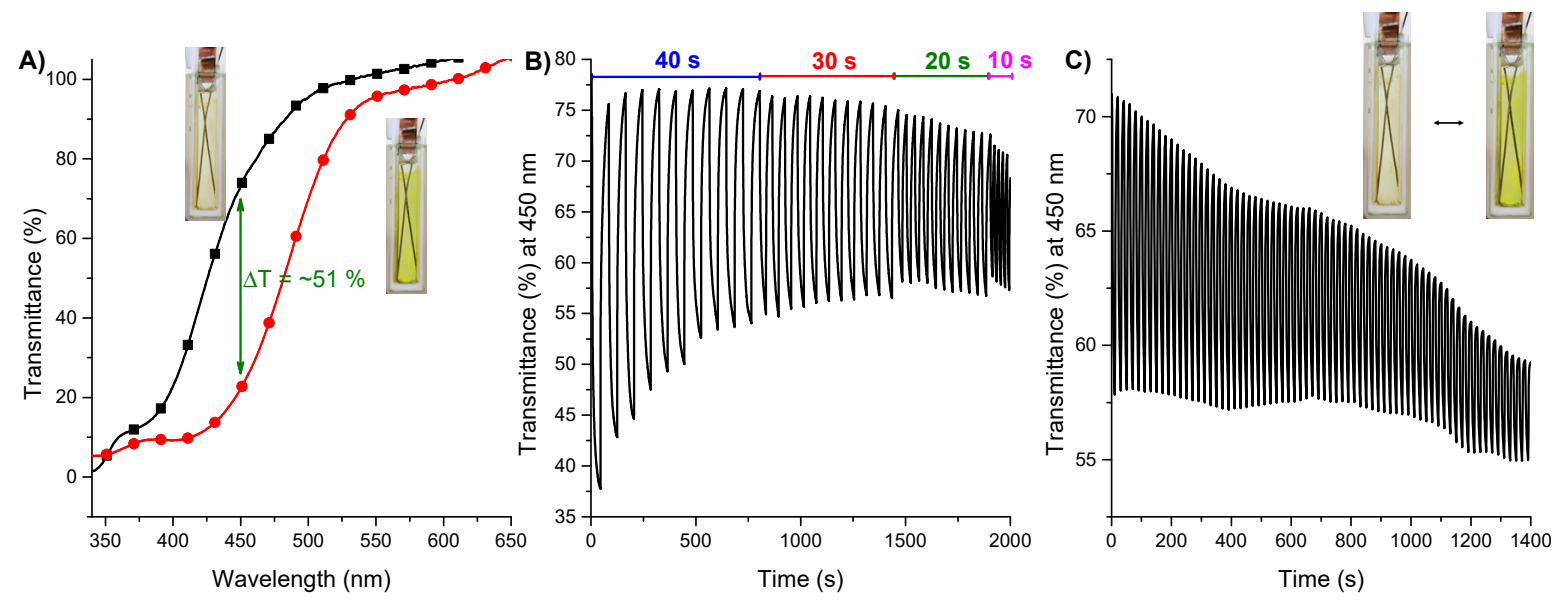

Figure 8. (A) The transmittance spectra of the poly-1 in oxidized (black) and reduced (red) form; (B) Electrochromic switching between oxidized and reduced form of poly-1 with intervals of 40, 30, 20 and 10 s monitored at $450 \mathrm{~nm}$; (C) The Transmittance difference of poly-1 by switching between oxidized and reduced states with $10 \mathrm{~s}$ intervals.

\section{Conclusions}

The terpyridine-like $\mathrm{N}_{3}$-donor ligand have been obtained via condensation of styrenesubstituted picolinaldehyde and benzimidazole-based hydrazine. The self-assembly of the ligand with $\mathrm{Fe}(\mathrm{II})$ ions led to formation of mononuclear complexes of metal:ligand ratio 1:2. The complex $\left[\mathrm{FeL}_{2}\right]\left(\mathrm{CF}_{3} \mathrm{SO}_{3}\right)_{2}$ was found to undergo reductive electropolymerization on the electrode surface forming the thin layer of polymer poly-1. Both the monomer and the polymer were found to undergo two quasi-reversible electrochemical processes with the visible color change from yellow to almost colorless during electrooxidation and to intense yellow during electroreduction of the metallic center. The color contrast of the polymer was investigated by switching between oxidized and reduced form (from almost colorless to bright yellow) with different time intervals from $40 \mathrm{~s}$ to $10 \mathrm{~s}$. The long-term stability of the film was investigated and it was found that the polymer partially decompose during multiple oxidation/reduction cycles. 
Supplementary Materials: Crystallographic data for the structural analysis have been deposited with the Cambridge Crystallographic Data Centre. Copies of this information may be obtained free of charge from: The Director, CCDC, 12 Union Road, Cambridge, CB2 1EZ, UK; e-mail: deposit@ccdc.cam.ac.uk, or www.ccdc.cam.ac.uk. The following are available online at https: / / www.mdpi.com/article/10.3390/ma14174831/s1, Figure S1: Cyclic voltammogram of complex 2 measured in anhydrous and deaerated acetonitrile with $0.1 \mathrm{M} \mathrm{TBAClO}_{4}$ as a supporting electrolyte at scan rate $100 \mathrm{mV} \cdot \mathrm{s}^{-1}$, Figure S2. Cyclic voltammogram of complex 1 measured in anhydrous and deaerated acetonitrile with $0.1 \mathrm{M} \mathrm{TBAClO}_{4}$ as a supporting electrolyte at scan rate $100 \mathrm{mV} \cdot \mathrm{s}^{-1}$ in the potential window from 0 to $+1.0 \mathrm{~V}$, Figure S3. Cyclic voltammogram of poly-1 measured in anhydrous and deaerated acetonitrile with $0.1 \mathrm{M} \mathrm{TBAClO}_{4}$ as a supporting electrolyte at scan rate $100 \mathrm{mV} \cdot \mathrm{s}^{-1}$, Figure S4. Spectroelectrochemistry of 1 measured in anhydrous and deaerated $0.1 \mathrm{M}$ solution of $\mathrm{TBAClO}_{4}$ in acetonitrile as a supporting electrolyte with applied potentials of (A) 0 $(\boldsymbol{\square}),+500(\bullet),+600(\Delta),+700(\nabla),+800(\diamond)$ and $+900(\triangleleft) \mathrm{mV}$ held for 30 s per potential; insert: the

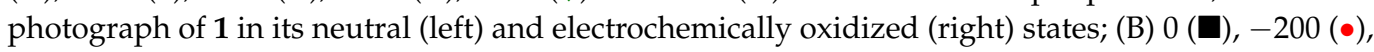
$-300(\Delta),-400(\nabla),-500(\diamond)$ and $-600(\Delta) \mathrm{mV}$ held for 30 s per potential; insert: the photograph of $\mathbf{1}$ in its neutral (left) and electrochemically reduced (right) states, Figure S5. The absorption spectra of poly-1 in its neutral Fe(II) state $(\boldsymbol{\square})$, oxidized Fe(III) state at $+1.0 \mathrm{~V}(\bullet)$ and reduced Fe(I) state $(\boldsymbol{\Delta})$ at $-0.5 \mathrm{~V}$, Figure S6. ${ }^{1} \mathrm{H}$ NMR of ligand $\mathbf{L}$ in $\mathrm{d}_{6}-\mathrm{DMSO}$, Figure $57 .{ }^{13} \mathrm{C}$ NMR spectra of ligand $\mathbf{L}$ in $\mathrm{d}_{6}$-DMSO, Figure S8. HR-MS spectra of ligand L, Figure S9. ESI-MS spectra of complex 1, Figure S10. ESI-MS spectra of complex 2.

Author Contributions: Conceptualization, M.W.-C.; methodology, M.W.-C., G.D.; investigation, S.N., K.M. and G.D.; resources, M.W.-C.; writing-original draft preparation, M.W.-C., G.D., S.N., K.M.; writing-review and editing, M.W.-C., G.D.; supervision, M.W.-C.; project administration, M.W.-C.; funding acquisition, M.W.-C. All authors have read and agreed to the published version of the manuscript.

Funding: The work was supported by grant SONATA 2016/21/D/ST5/01631 financed by the National Science Centre, Poland.

Institutional Review Board Statement: Not applicable.

Informed Consent Statement: Not applicable.

Data Availability Statement: Data is contained within the article.

Conflicts of Interest: The authors declare no conflict of interest.

\section{References}

1. Friebe, C.; Hager, M.D.; Winter, A.; Schubert, U. Metal-containing Polymers via Electropolymerization. Adv. Mater. 2011, 24, 332-345. [CrossRef]

2. Tao, Y.; Zhang, K.; Zhang, Z.; Cheng, H. Novel electrochromic copolymers based on thiophene-anthracene derivatives via electrochemical polymerization in boron trifluoride diethyl etherate. J. Electroanal. Chem. 2016, 769, 80-88. [CrossRef]

3. Kuo, C.-W.; Lee, P.-Y. Electrosynthesis of Copolymers Based on 1,3,5-Tris(N-Carbazolyl)Benzene and 2,2'-Bithiophene and Their Applications in Electrochromic Devices. Polymers 2017, 9, 518. [CrossRef]

4. Xu, Z.; Yue, H.; Wang, B.; Zhao, J.; Wang, M.; Zhang, Y.; Xie, Y. Color tuning for black-to-transmissive conjugated copolymer with excellent electrochromic properties via electrochemical copolymerization of two donor-acceptor type monomers. Mater. Des. 2020, 194, 108903. [CrossRef]

5. Napierała, S.; Kubicki, M.; Patroniak, V.; Wałęsa-Chorab, M. Electropolymerization of [2 × 2] grid-type cobalt(II) complex with thiophene substituted dihydrazone ligand. Electrochim. Acta 2021, 369, 137656. [CrossRef]

6. Abe, M.; Futagawa, H.; Ono, T.; Yamada, T.; Kimizuka, N.; Hisaeda, Y. An Electropolymerized Crystalline Film Incorporating Axially-Bound Metalloporphycenes: Remarkable Reversibility, Reproducibility, and Coloration Efficiency of Ruthenium(II/III)Based Electrochromism. Inorg. Chem. 2015, 54, 11061-11063. [CrossRef] [PubMed]

7. Palma-Cando, A.; Scherf, U. Electrochemically Generated Thin Films of Microporous Polymer Networks: Synthesis, Properties, and Applications. Macromol. Chem. Phys. 2016, 217, 827-841. [CrossRef]

8. Gu, C.; Huang, N.; Chen, Y.; Zhang, H.; Zhang, S.; Li, F.; Ma, Y.; Jiang, D. Porous Organic Polymer Films with Tunable Work Functions and Selective Hole and Electron Flows for Energy Conversions. Angew. Chem. Int. Ed. 2016, 55, 3049-3053. [CrossRef] [PubMed]

9. Zhong, Y.-W.; Yao, C.-J.; Nie, H.-J. Electropolymerized films of vinyl-substituted polypyridine complexes: Synthesis, characterization, and applications. Coord. Chem. Rev. 2013, 257, 1357-1372. [CrossRef] 
10. Cui, B.-B.; Yao, C.-J.; Yao, J.; Zhong, Y.-W. Electropolymerized films as a molecular platform for volatile memory devices with two near-infrared outputs and long retention time. Chem. Sci. 2013, 5, 932-941. [CrossRef]

11. Cui, B.-B.; Nie, H.-J.; Yao, C.-J.; Shao, J.-Y.; Wu, S.-H.; Zhong, Y.-W. Reductive electropolymerization of bis-tridentate ruthenium complexes with 5,5??-divinyl-4?-tolyl-2,2?:6?,2??-terpyridine. Dalton Trans. 2013, 42, 14125. [CrossRef] [PubMed]

12. Tang, J.-H.; He, Y.-Q.; Shao, J.-Y.; Gong, Z.-L.; Zhong, Y.-W. Multistate Redox Switching and Near-Infrared Electrochromism Based on a Star-Shaped Triruthenium Complex with a Triarylamine Core. Sci. Rep. 2016, 6, 35253. [CrossRef] [PubMed]

13. Yao, C.-J.; Zhong, Y.-W.; Nie, H.-J.; Abruña, H.D.; Yao, J. Near-IR Electrochromism in Electropolymerized Films of a Biscyclometalated Ruthenium Complex Bridged by 1,2,4,5-Tetra(2-pyridyl)benzene. J. Am. Chem. Soc. 2011, 133, 20720-20723. [CrossRef] [PubMed]

14. Wu, L.; Brennaman, M.K.; Nayak, A.; Eberhart, M.; Miller, A.J.M.; Meyer, T.J. Stabilization of Ruthenium(II) Polypyridyl Chromophores on Mesoporous $\mathrm{TiO}_{2}$ Electrodes: Surface Reductive Electropolymerization and Silane Chemistry. ACS Cent. Sci. 2019, 5, 506-514. [CrossRef] [PubMed]

15. Yao, C.-J.; Yao, J.; Zhong, Y.-W. Metallopolymeric Films Based on a Biscyclometalated Ruthenium Complex Bridged by 1,3,6,8Tetra(2-pyridyl)pyrene: Applications in Near-Infrared Electrochromic Windows. Inorg. Chem. 2012, 51, 6259-6263. [CrossRef]

16. Calvert, J.M.; Schmehl, R.H.; Sullivan, B.P.; Facci, J.S.; Meyer, T.J.; Murray, R.W. Synthetic and mechanistic investigations of the reductive electrochemical polymerization of vinyl-containing complexes of iron(II), ruthenium(II), and osmium(II). Inorg. Chem. 1983, 22, 2151-2162. [CrossRef]

17. Abruna, H.D.; Denisevich, P.; Umana, M.; Meyer, T.J.; Murray, R.W. Rectifying interfaces using two-layer films of electrochemically polymerized vinylpyridine and vinylbipyridine complexes of ruthenium and iron on electrodes. J. Am. Chem. Soc. 1981, 103, 1-5. [CrossRef]

18. Shao, J.-Y.; Yao, C.-J.; Cui, B.-B.; Gong, Z.-L.; Zhong, Y.-W. Electropolymerized films of redox-active ruthenium complexes for multistate near-infrared electrochromism, ion sensing, and information storage. Chin. Chem. Lett. 2016, 27, 1105-1114. [CrossRef]

19. Bommarito, S.L.; Lowery-Bretz, S.P.; Abruna, H.D. Synthesis and characterization of redox copolymers of tris(4-vinyl-4'-methyl2,2'-bipyridine)ruthenium(2+) and tris(4-vinyl-4'-methyl-2,2'-bipyridine)osmium(2+): Unusual energy-transfer dynamics. Inorg. Chem. 1992, 31, 502-507. [CrossRef]

20. Napierała, S.; Wałęsa-Chorab, M. On-substrate postsynthetic metal ion exchange as a tool for tuning electrochromic properties of materials. Eur. Polym. J. 2020, 140, 110052. [CrossRef]

21. Wałęsa-Chorab, M.; Skene, W.G. Engaging the Reversible Bonds of an Immobilized Styreno-Thiophene Film. Cryst. Growth Des. 2020, 20, 5688-5697. [CrossRef]

22. Harzmann, G.D.; Neuburger, M.; Mayor, M. 4,4-Disubstituted Terpyridines and Their Homoleptic Fe II Complexes. Eur. J. Inorg. Chem. 2013, 2013, 3334-3347. [CrossRef]

23. Potts, K.T.; Cipullo, M.J.; Ralli, P.; Theodoridis, G. Ketenedithioacetals as synthetic intermediates. A versatile synthesis of pyridenes, polypyridinyls, and pyrylium salts. J. Am. Chem. Soc. 1981, 103, 3585-3586. [CrossRef]

24. Yamamoto, Y.; Tanaka, T.; Yagi, M.; Inamoto, M. Studies on Organometallic Compounds. IX. Synthesis of Bipyride N-Oxides and Terpyridines by Palladium Catalyzed Cross-Coupling Reaction of Trimethylstannylpyridines with Bromopyridines. HeteroCycles 1996, 42, 189. [CrossRef]

25. Clarke, C.; Tu, W.-C.; Levers, O.; Bröhl, A.; Hallett, J.P. Green and Sustainable Solvents in Chemical Processes. Chem. Rev. 2018, 118, 747-800. [CrossRef]

26. Marcinkowski, D.; Wałęsa-Chorab, M.; Bocian, A.; Mikołajczyk, J.; Kubicki, M.; Hnatejko, Z.; Patroniak, V. The spectroscopic studies of new polymeric complexes of silver(I) and original mononuclear complexes of lanthanides(III) with benzimidazole-based hydrazone. Polyhedron 2017, 123, 243-251. [CrossRef]

27. Povstyanoi, M.V.; Kruglenko, V.P.; Fedosenko, E.N.; Klyuev, N.A. Condensed imidazo-1,2,4-triazines. 23. Synthesis and reactions of 2-(1-alkylhydrazino)-benzimidazole with acetyl(benzoyl)acetone. Chem. Heterocycl. Compd. 1990, 26, 891-893. [CrossRef]

28. Williams, D.B.G.; Lawton, M. Drying of Organic Solvents: Quantitative Evaluation of the Efficiency of Several Desiccants. J. Org. Chem. 2010, 75, 8351-8354. [CrossRef] [PubMed]

29. 29. CrysAlis PRO, Version 1.171.40.53, Rigaku Oxford Diffraction, Rigaku Corporation, Oxford, UK. 2019.

30. Sheldrick, G.M. SHELXT-Integrated space-group and crystal-structure determination. Acta Crystallogr. Sect. A Found. Adv. 2015, 71, 3-8. [CrossRef]

31. Sheldrick, G.M. Crystal structure refinement with SHELXL. Acta Crystallogr. Sect. C Struct. Chem. 2015, 71, 3-8. [CrossRef] [PubMed]

32. Hamon, P.; Toupet, L.; Roisnel, T.; Hamon, J.-R.; Lapinte, C. Preparation and Characterization of the Triflate Complex $\left[\mathrm{Cp}^{*}(\mathrm{dppe}) \mathrm{FeOSO}_{2} \mathrm{CF}_{3}\right]$ : A Convenient Access to Labile Five- and Six-Coordinate Iron(I) and Iron(II) Complexes. Eur. J. Inorg. Chem. 2019, 2020, 84-93. [CrossRef]

33. Bocian, A.; Napierała, S.; Gorczyński, A.; Kubicki, M.; Wałęsa-Chorab, M.; Patroniak, V. The first example of an asymmetrical $\mu$-oxo bridged dinuclear iron complex with a terpyridine ligand. New J. Chem. 2019, 43, 12650-12656. [CrossRef]

34. Wałęsa-Chorab, M.; Banasz, R.; Marcinkowski, D.; Kubicki, M.; Patroniak, V. Electrochromism and electrochemical properties of complexes of transition metal ions with benzimidazole-based ligand. RSC Adv. 2017, 7, 50858-50867. [CrossRef]

35. Bard, A.J.; Faulkner, L.R. Electrochemical Methods-Fundamentals and Applications, 2nd ed.; Wiley: New York, NY, USA, 2001.

36. Eckermann, A.; Feld, D.J.; Shaw, J.A.; Meade, T.J. Electrochemistry of redox-active self-assembled monolayers. Coord. Chem. Rev. 2010, 254, 1769-1802. [CrossRef] [PubMed] 
37. Wang, J. Analytical Electrochemistry; Wiley: New York, NY, USA, 2006.

38. Kuai, Y.; Li, W.; Dong, Y.; Wong, W.-Y.; Yan, S.; Dai, Y.; Zhang, C. Multi-color electrochromism from coordination nanosheets based on a terpyridine-Fe(ii) complex. Dalton Trans. 2019, 48, 15121-15126. [CrossRef]

39. Mondal, S.; Ninomiya, Y.; Yoshida, T.; Mori, T.; Bera, M.K.; Ariga, K.; Higuchi, M. Dual-Branched Dense Hexagonal Fe(II)-Based Coordination Nanosheets with Red-to-Colorless Electrochromism and Durable Device Fabrication. ACS Appl. Mater. Interfaces 2020, 12, 31896-31903. [CrossRef] [PubMed]

40. Banasz, R.; Kubicki, M.; Wałęsa-Chorab, M. Yellow-to-brown and yellow-to-green electrochromic devices based on complexes of transition metal ions with a triphenylamine-based ligand. Dalton Trans. 2020, 49, 15041-15053. [CrossRef] [PubMed]

41. Li, X.; Zhang, W.; Wang, Y.-C.; Zhang, W.; Wang, H.-Q.; Fang, J. In-situ cross-linking strategy for efficient and operationally stable methylammoniun lead iodide solar cells. Nat. Commun. 2018, 9, 1-10. [CrossRef] [PubMed]

42. Wałesa-Chorab, M.; Banasz, R.; Kubicki, M.; Patroniak, V. Dipyrromethane functionalized monomers as precursors of electrochromic polymers. Electrochim. Acta 2017, 258, 571-581. [CrossRef]

43. Hibon, P.; Von Seggern, H.; Tseng, H.; Leonhard, C.; Hamburger, M.; Béalle, G. Improved thin film stability of differently formulated, printed, and crosslinked polymer layers against successive solvent printing. J. Appl. Polym. Sci. 2020, 137, 48895. [CrossRef] 